THE JOURNAL OF INFECTIOUS DISEASES - VOL. 157, NO. 5 - MAY 1988

(C) 1988 by The University of Chicago. All rights reserved. $0022-1899 / 88 / 5705-0018 \$ 01.00$

\title{
Predictors of Endocarditis in Isolates from Cultures of Blood Following Dental Extractions in Rats with Periodontal Disease
}

\author{
P. Moreillon, C. D. Overholser, R. Malinverni, \\ J. Bille, and M. P. Glauser
}

\author{
From the Department of Internal Medicine, Division of \\ Infectious Diseases, Centre Hospitalier Universitaire Vaudois, \\ Lausanne, Switzerland; and the Department of \\ Oral Diagnosis, Baltimore College of Dental Surgery, \\ Dental School, University of Maryland at Baltimore, \\ Baltimore, Maryland
}

\begin{abstract}
Rats with periodontitis and catheter-induced aortic valve vegetations underwent dental extractions. Cultures of blood obtained $1 \mathrm{~min}$ later showed polymicrobial bacteremia in 19 of 19 rats, mostly due to viridans streptococci (18 of 19), Morganella (15 of 19), group G streptococci (13 of 19), and Staphyiococcus aureus (10 of 19). Viridans streptococci circulated in higher numbers than did group $G$ streptococci and $S$, aureus $(P<.01)$. Three days after dental extractions, 18 of 20 rats had endocarditis. Fifteen (83\%) of 18 infections were due to group $G$ streptococci, $9(50 \%)$ of 18 were due to $S$. aureus, and $2(11 \%)$ of 18 were due to viridans streptococci $(P<.05)$. In vitro, adherence to platelet-fibrin matrices of endocarditis strain 8 of group $G$ streptococcus was two times greater than that of endocarditis strain $S$. aureus 23 and three to four times greater than that of Streptococcus sanguis 44 and Morganella morganii $93\left(P<10^{-5}\right)$. The inoculum size that produced endocarditis in $90 \%$ of rats after iv challenge was $10^{5}$ cfu for group $\mathrm{G}$ streptococcus strain 8 and $10^{7}$ for $S$. sanguis 44 .
\end{abstract}

Studies of experimental endocarditis performed both in vitro and in vivo have demonstrated that after iv injections of bacteria into rabbits or into rats with catheter-induced, sterile aortic vegetations, both the number of bacteria used for iv challenge and their ability to stick to the sterile vegetations were critical factors that enabled them to induce bacterial endocarditis [1-3]. In these studies, however, the animals were infected with large bacterial inocula from single bacterial strains; this inoculation resulted in high levels of monomicrobial bacteremia, which was obviously different from the transient, low-grade polymicrobial bacteremia following dental extractions or other procedures that might induce bacteremia in humans [4-8]. In such circumstances it is usually

Received for publication 21 August 1987 and in revised form 3 December 1987.

This work was presented in part (abstract no. 465) at the 25th Interscience Conference on Antimicrobial Agents and Chemotherapy, held in Minneapolis, on 29 September-2 October 1985.

This work was supported by grant $3.847-0.83$ from the Swiss National Foundation.

We thank Marlyse Giddey for technical work and Sylviane Bovey for typing the manuscript.

Please address requests for reprints to Dr. M. P. Glauser, Département de Médecine Interne, Division des Maladies Infectieuses, Centre Hospitalier Universitaire Vaudois, 1012 Lausanne, Switzerland. thought that the number of circulating microorganisms of a given bacterial strain might best predict the occurrence of endocarditis.

In the present study we investigated the natural history of experimental bacterial endocarditis after dental extractions in rats by using a model of periodontal disease in these animals [9]. We performed serial cultures of blood immediately after dental extractions and attempted to correlate the findings with the subsequent development of endocarditis.

\section{Materials and Methods}

Induction of periodontal disease. Periodontal disease was induced in 200-g, female Wistar rats by a recently described technique [9]. In brief, gingival irritation was produced by placing silk ligatures at the cervical margin of the right and left first maxillary molars. These ligatures were left in place during the remainder of the experiment. The animals were then maintained on a high-sucrose diet (Keyes diet 2000; Tekland, Madison, Wis) ad libitum for 16 w. Such a regimen was sufficient to induce periodontal lesions in the rats [9].

Production of sterile aortic valve vegetations. Sixteen weeks after placing the ligatures and starting the high-sucrose diet, when periodontal disease was established, sterile aortic valve vegetations were 
produced in the rats by means of a polyethylene catheter (PP10; Portex, Hythe, Kent, England) inserted via the right carotid artery through the aortic valve [10]. The catheter was secured with a silk ligature and left in place until the animals were killed.

Cultures of gingiva and blood and dental extractions. Twenty-four hours after catheterization, the rats with gingival ligatures were anesthetized, and the presence of periodontal disease was assessed in each animal by one of us (C. D. O.). Gingival cultures were performed by atraumatic collection of samples of dental plaque from the two periodontally diseased molars. The plaque material was suspended in $0.9 \% \mathrm{NaCl}$ and plated onto blood agar for qualitative cultures. Just after gingival cultures, the two teeth with periodontal disease were extracted, a procedure that lasted $\sim 4 \mathrm{~min}$. One minute after the end of the dental extractions, $0.5 \mathrm{~mL}$ of blood was drawn from a jugular vein and immediately plated onto blood agar for quantitative cultures of blood.

Killing of animals. Three days after the dental extractions, the rats were killed as previously described $[2,10]$. The valves were aseptically excised, weighed, homogenized in $0.9 \% \mathrm{NaCl}$, and serially diluted before plating onto blood agar. The dilution technique permitted the detection of $10^{2} \mathrm{cfu} / \mathrm{g}$ of tissue. The presence of postextraction bacterial endocarditis was defined as positive valve cultures after $48 \mathrm{~h}$ of incubation at $37 \mathrm{C}$.

Microbiological analysis. The gingival and blood specimens were plated for aerobic cultures. Because in previous experiments with this animal model we did not induce any endocarditis due to anaerobic microorganisms after dental extractions, the gingival and blood specimens were not cultured under anaerobic conditions [9]. As a control, however, the cultures of the vegetations were incubated in both aerobic and anaerobic conditions, as in previous experiments, by using the Gas-Pak ${ }^{\circledR}$ Catalyst system (BBL, Cockeysville, Md). After $48 \mathrm{~h}$ of incubation at $37 \mathrm{C}$, all the microorganisms isolated from the different cultures were speciated using the API ${ }^{\circledR}$ system (Analytab Products, Plainview, NY).

In vitro adherence assay. Using a previously described in vitro assay system of platelet-fibrin matrices [3] simulating sterile vegetations, we tested the in vitro adherence of some representative microorganisms isolated from postextraction cultures of blood and from postextraction endocarditis. In brief, the microorganisms were grown overnight in trypticsoy broth (Difco, Detroit) enriched with $5 \%$ sucrose and serially diluted in PBS ( $\mathrm{pH} 7.4$ ) to obtain a concentration of $\sim 10^{4} \mathrm{cfu} / \mathrm{mL}$. These suspensions were immediately poured onto platelet-fibrin matrices contained in petri dishes and incubated for $3 \mathrm{~min}$ at $37 \mathrm{C}$ in a rotating incubator (at $120 \mathrm{rpm}$ ). The supernatants were discarded, and the matrices were washed three times for $5 \mathrm{~min}$ with PBS to eliminate the nonadherent bacteria. Blood agar was then poured on the matrices, and the adherent colonies were counted after $48 \mathrm{~h}$ of incubation at $37 \mathrm{C}$. The percentage of adherent colonies (adherence ratio) for each sample was defined as the number of colonies adherent to the matrix multiplied by 100 and divided by the initial number of cfu in the inoculum. The results were expressed as the mean of two or more separate experiments for each test microorganism, with each experiment consisting of at least six separate determinations.

Experimental endocarditis following injections with two streptococcal strains isolated after extraction. Two streptococcal strains isolated from the postextraction cultures of blood (Streptococcus sanguis 44 and group $\mathrm{G}$ streptococcus strain 8 ) of rats that subsequently developed endocarditis due to these microorganisms were tested for their ability to induce endocarditis after iv challenge of rats with catheter-induced, sterile aortic vegetations. In brief, groups of rats received iv injections of various bacterial inocula from an overnight culture (in trypticsoy broth plus $5 \%$ sucrose) of either $S$. sanguis 44 or group $\mathrm{G}$ streptococcus strain 8 diluted in $0.9 \%$ $\mathrm{NaCl}$. Three days after challenge the rats were killed as previously described. The incidence of bacterial endocarditis was determined for each inoculum size, and the minimal inoculum that produced endocarditis in $90 \%$ of the animals was defined as the $90 \%$ infective dose $\left(\mathrm{ID}_{90}\right)$.

Statistical analysis. The $\chi^{2}$ test with Yates's correction, the Student's $t$ test, and the Mann-Whitney test were used for statistical analyses.

\section{Results}

Periodontal status. Sixteen weeks after placing the ligatures and starting the high-sucrose diet in a group of 20 rats, all animals had evidence of periodontal disease, as defined by the presence of dental plaque and by erythematous enlargement of the gingiva next to the ligatures [9]. All of these rats underwent further dental extractions.

Postextraction cultures of blood. Cultures of 
blood obtained 1 min after the end of dental extractions were successfully obtained from 19 of the 20 rats. All of them had polymicrobial bacteremia (figure 1). The four bacterial species isolated most frequently from the blood $1 \mathrm{~min}$ after dental extractions were viridans streptococci, gram-negative bacilli (mostly Morganella morganii), group G streptococci, and coagulase-positive staphylococci (Staphylococcus aureus). There was a predominance in the incidence of circulating viridans streptococci and gram-negative bacilli (18 of 19 and 15 of 19 rats, respectively, had positive cultures of blood for these microorganisms) when compared with the incidence of circulating group G streptococci and $S$. aureus (13 of 19 and 10 of 19 rats, respectively, had positive cultures).

Viridans streptococci were also the microorganisms circulating in the highest number after dental extractions (median, 20; range, 0-200), followed by gram-negative bacilli (median, 11; range, 0-80), group G streptococci (median, 4; range, 0-20), and $S$. aureus (median, 2; range, $0-142$ ). The average number of circulating viridans streptococci was significantly higher than the average number of circulating group G streptococci or $S$. aureus $(P<.01$ when compared by the Mann-Whitney test).

Incidence of postextraction endocarditis. Eighteen $(90 \%)$ of the 20 rats developed postextraction endocarditis: $10(55 \%)$ with monomicrobial infections (7 due to group G streptococci and 3 due to $S$. aureus) and $8(45 \%)$ with polymicrobial infections $(6$ due to group $\mathrm{G}$ streptococci plus $S$. aureus and 2 due to group $G$ streptococci plus viridans streptococci). Thus, the microorganisms isolated most frequently from the infected vegetations were (figure 1) group $G$ streptococci in $15(83 \%)$ of 18 rats, followed by S. aureus in $9(50 \%)$ of 18 rats and viridans streptococci in only $2(11 \%)$ of 18 rats. The incidence of endocarditis due to group G streptococci or to $S$. aureus was significantly higher than the incidence of endocarditis due to viridans streptococci $(P<.01$, when compared by the $\chi^{2}$ test with Yates's correction). There was no endocarditis due to gram-negative bacilli or to anaerobic microorganisms.

Relations between gingival cultures, bacteremia, and endocarditis. In all of the rats, microorganisms recovered from the cultures of blood and from the infected vegetations were also recovered from the gingival cultures. With regard to the relation between the cultures of blood and the development of subsequent endocarditis, there were discrepancies (figure 1). Indeed, despite high levels of postextraction

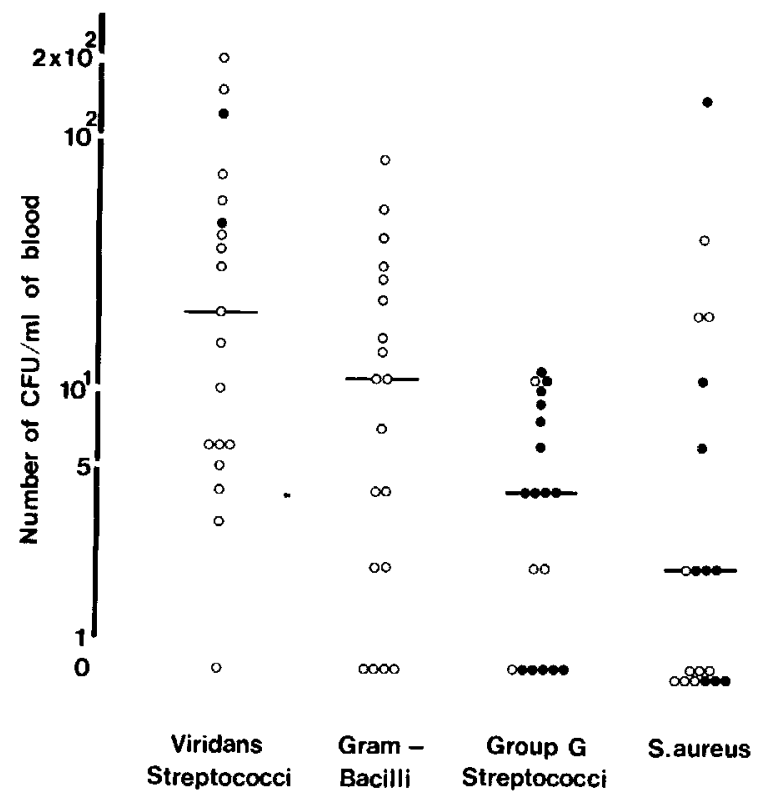

Figure 1. The number of $\mathrm{cfu} / \mathrm{mL}$ of blood from the most frequently isolated bacterial species in 19 rats $1 \mathrm{~min}$ after dental extractions. Each circle represents the value for one particular rat. The closed circles represent the rats that developed bacterial endocarditis due to the same bacterial species following dental extractions, and the open circles represent the rats that did not develop endocarditis. The average number of viridans streptococci and the average numbers of group G streptococci and of $S$. aureus were significantly different $(P<.01$, by Mann-Whitney test).

bacteremia, viridans streptococci induced endocarditis in only two of 20 rats; gram-negative bacilli did not induce any endocarditis at all. In contrast, there was a striking predominance of endocarditis due to group G streptococci and $S$. aureus despite significantly lower numbers of circulating bacteria $1 \mathrm{~min}$ after dental extractions. Moreover, in as many as onethird of the rats with group $G$ streptococcal endocarditis ( 5 of 15 rats) and one-third of the rats with $S$. aureus endocarditis ( 3 of 9 rats), the postextraction cultures of blood did not yield any group $G$ streptococci or $S$. aureus. Thus, there was no relation between the level of postextraction bacteremia and the occurrence of subsequent endocarditis.

In vitro adherence of the bacteria frequently isolated from cultures of blood. The in vitro adherence ratio of a representative strain of group G streptococcus (strain 8) was $0.58 \pm 0.2$ (mean $\pm \mathrm{SD}$ of 96 determinations). In comparison, the adherence ratio of a representative strain of $S$. aureus (S. aureus 


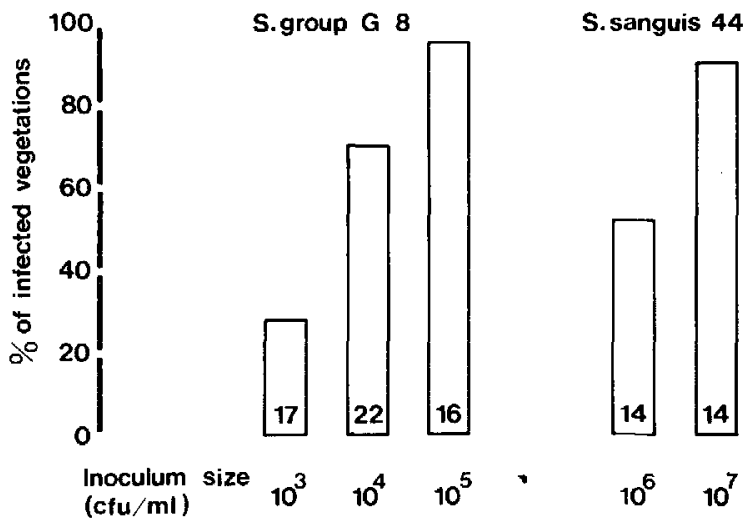

Figure 2. The incidence of endocarditis after iv challenge with various inoculum sizes of group $\mathrm{G}$ streptococcus strain $8(S$. group $G 8)$ or $S$. sanguis 44 in rats with catheterinduced aortic vegetations. Indicated at the base of each column are the sizes of the bacterial inocula used for iv challenge. Indicated within each column are the total numbers of rats in each experimental group.

23) was $0.25 \pm 0.1$ (mean \pm SD of 12 determinations), i.e., two times less than that of group $\mathrm{G}$ streptococcus strain $8\left(P<10^{-3}\right)$, and the adherence ratios of representative strains of viridans streptococci (S. sanguis 44) and Morganella (M. morganii 93) were $0.18 \pm 0.1$ and $0.15 \pm 0.1$, respectively (mean \pm SD of 48 determinations in both cases), i.e., three to four times less than the adherence ratio of group $\mathrm{G}$ streptococcus strain $8\left(P<10^{-5}\right)$. Thus, there was an apparent relation between the in vitro stickiness of the representative strains of the bacterial species found in the cultures of blood after dental extractions and the ability of these microorganisms to induce endocarditis.

Experimental endocarditis after iv injections with two streptococcal strains. To further evaluate the relation between the in vitro adherence to plateletfibrin matrices of a given bacterial strain and its ability to induce endocarditis in vivo, we determined for group G streptococcus strain 8 and for $S$. sanguis 44 the minimal bacterial inocula necessary to induce endocarditis in $90 \%$ of the animals (i.e., the $\mathrm{ID}_{90}$; figure 2). For group $\mathrm{G}$ streptococcus strain 8 , whose adherence in vitro was the highest, the $\operatorname{ID}_{90}$ was $10^{5}$ $\mathrm{cfu}$, whereas for $S$. sanguis 44 , whose in vitro adherence was the lowest, the $\mathrm{ID}_{g_{0}}$ was $10^{7} \mathrm{cfu}$. Thus, there was a relation between the adherence of these bacterial isolates in vitro and their ability to induce endocarditis in vivo.

\section{Discussion}

The observations in the present experiments resemble the situation in dental patients, in whom transient polymicrobial bacteremia of dental origin have been observed following dental extractions in up to $80 \%$ of cases $[8,11]$. Indeed, in rats with periodontal disease, all of the animals tested had polymicrobial bacteremia 1 min after dental extractions; the bacteremia was due to microorganisms similar to those recovered on the rats' dental plaque. Thus, the present model of experimental endocarditis following dental extractions in rats mimics the pathogenesis of endocarditis in humans more closely than did previous animal models, in which the valves were infected with iv injections of large sizes of bacterial inocula from single bacterial strains, resulting in a high level of monomicrobial bacteremia $[2,4-6,10]$.

Previous studies of endocarditis in rabbits and in rats have shown that after iv challenge with a pure culture of a given bacterial strain, there was a close relation between the inoculum size used for challenge and the subsequent incidence of endocarditis $[2,12]$. Wide variations were observed, however, in the ability to induce endocarditis within similar streptococcal types and among different bacterial species [2, 12, 13].

In the present experiments there was no direct relation between the number of bacteria circulating in the blood after dental extractions and the incidence of subsequent bacterial endocarditis. Indeed, despite low or undetectable numbers of circulating microorganisms 1 min after dental extractions, group $G$ streptococci and $S$. aureus induced endocarditis more frequently $(P<.05)$ than did viridans streptococci and gram-negative bacilli, which were recovered more consistently and in higher numbers from the cultures of blood. Because preliminary experiments with this animal model showed that $5 \mathrm{~min}$ after dental extractions the cultures of blood were consistently sterile (data not shown), the postextraction endocarditis due to group $G$ streptococci and to $S$. aureus were probably due to bacteremia that occurred before the time of postextraction cultures of blood (i.e., before the first minute after dental extractions). One possible explanation for this lack of relation between circulating bacterial numbers and the development of endocarditis might be that some occult bacteremia (e.g., delayed bacteremia or longlasting, very-low-grade bacteremia caused by exposure of the opened wound to the salivary flora) re- 
mained undetectable by cultures of blood performed 1 and 5 min after dental extractions. An alternative, more likely explanation is that group $\mathrm{G}$ streptococci and $S$. aureus had special properties that enabled them to colonize and infect damaged valves despite low numbers of circulating bacteria. Indeed, it was striking that group $\mathrm{G}$ streptococci, the bacterial type that adhered best to platelet-fibrin matrices in vitro, were those that produced the highest frequency of endocarditis, despite inconsistent detection in cultures of blood after dental extractions (and when detected, despite low circulating numbers). This relation between the incidence of endocarditis and the in vitro adherence properties was confirmed when group $\mathrm{G}$ streptococci were injected iv into rats with catheter-induced, sterile aortic vegetations: only $10^{5}$ cfu of the sticky group $\mathrm{G}$ streptococcus strain 8 were sufficient to produce bacterial endocarditis in $90 \%$ of the rats $\left(\mathrm{ID}_{90}\right) ; 100$ times more cfu of the less sticky $S$. sanguis 44 were necessary to achieve a similar incidence. Thus, group G streptococcus strain 8 was found to be among the most virulent nonenterococcal streptococcal strains tested in this model. When comparing the relatively high numbers of bacteria necessary to produce endocarditis after iv injection and the low numbers of group $G$ streptococcus strain 8 circulating after dental extractions, it should be remembered that the number of bacteria injected iv into animals does not represent the number of bacteria that circulate and that the bacterial numbers found in the hearts of the animals after iv injections are far below the original inoculum, thanks to both a passive hemodilution phenomenon and an active clearance mechanism by the reticuloendothelial system. Therefore, in the present experiments, in vitro stickiness, not the magnitude of bacteremia $1 \mathrm{~min}$ after dental extractions, correlated best with the ability of group G streptococci and of $S$. aureus to induce bacterial endocarditis.

In humans, as was observed in the present experiments, the cultures of blood performed during dental or medical procedures that might induce bacteremia yield many bacteria that do not produce endocarditis; bacteria known to produce endocarditis in humans, such as viridans streptococci, can be isolated in only one-third of such specimens [14]. Thus, both experimental and clinical observations suggest that certain microorganisms might have particular properties that enable them to induce endocarditis. These properties include the ability to resist host defense mechanisms such as preformed antibodies [15-17], complement-mediated bacterial killing [18], and phagocytosis by blood leukocytes $[19,20]$. In addition, the ability to adhere to the sterile vegetations present on the surface of damaged valves has been recognized as one of the most important mechanisms in the pathogenesis of bacterial endocarditis $[3,21]$.

There was a predominance of endocarditis due to group G streptococci and to $S$. aureus in the rats after dental extractions, in contrast to the predominance of endocarditis due to viridans streptococci that follows dental extractions in humans [22]. This result is best explained by the different bacterial floras in the mouths of rats and humans-both group G streptococci and $S$. aureus are present in large numbers in the area of periodontally diseased teeth in rats (while usually absent in human periodontitis [23]). This occurrence allows these bacteria to invade the blood stream during dental extractions and to induce bacterial endocarditis thereafter. The tendency of group G streptococci and of $S$. aureus to produce mixed infections (they grew in association in six of eight of the valves with polymicrobial infections) remains unexplained, but such a propensity has also been observed in humans $[24,25]$ and might possibly be related to the high affinity of these two microorganisms to bind to fibronectin, a protein that promotes the adherence of bacteria to several animal proteins, including collagen, fibrin clots, and valvular vegetations [26-28].

In conclusion, in the present experiments, the parameter that best predicted the likelihood of producing bacterial endocarditis among isolates of bacteria from the blood after dental extractions was the in vitro stickiness of a given bacterial strain, not the number of bacteria circulating $1 \mathrm{~min}$ after cxtractions. Thus, determining the magnitude of bacteremia after certain procedures might not provide reliable information on the risk of subsequent development of bacterial endocarditis.

\section{References}

1. Durack DT, Beeson PB, Petersdorf RG. Experimental bacterial endocarditis. III. Production and progression of the disease in rabbits. Br J Exp Pathol 1973;54:142-51

2. Glauser MP, Bernard JP, Moreillon P, Francioli P. Successful single-dose amoxicillin prophylaxis against experimental streptococcal endocarditis: evidence of two mechanisms for protection. J Infect Dis 1983;147:568-75

3. Scheld WM, Valone JA, Sande MA. Bacterial adherence in the pathogenesis of endocarditis. Interaction of bacterial dextran, platelets, and fibrin. J Clin Invest 1978;61:1394-404 
4. Durack DT, Beeson PB. Experimental bacterial endocarditis. I. Colonization of a sterile vegetation. Br J Exp Pathol 1972;53:44-9

5. Adler SW, Selinger DS, Reed WP. Effect of immunization on the genesis of pneumococcal endocarditis in rabbits. Infect Immun 1981;34:55-61

6. Lowy FD, Chang DS, Neuhaus EG, Horne DS, Tomasz A, Steigbigel NH. Effect of penicillin on the adherence of Streptococcus sanguis in vitro and in the rabbit model of endocarditis. J Clin Invest 1983;71:668-75

7. Okell CC, Elliot SD. Bacteriaemia and oral sepsis, with special reference to aetiology of subacute endocarditis. Lancet $1935 ; 2: 869-72$

8. Everett ED, Hirschmann JV. Transient bacteremia and endocarditis prophylaxis: a review. Medicine (Baltimore) 1977 56:61-77

9. Overholser CD, Moreillon P, Glauser MP. Experimental bacterial endocarditis after dental extractions in rats with periodontitis. J Infect Dis 1987;155:107-12

10. Heraief E, Glauser MP, Freedman LR. Natural history of aortic valve endocarditis in the rat. Infect Immun 1982;37: 127-31

11. Guntheroth WG. How important are dental procedures as a cause of infective endocarditis. Am J Cardiol 1984;54: 797-801

12. Francioli P, Moreillon P, Glauser MP. Comparison of single doses of amoxicillin or of amoxicillin-gentamicin for the prevention of endocarditis caused by Streptococcus faecalis and by viridans streptococci. J Infect Dis 1985;152:83-9

13. Freedman LR, Valone J. Experimental endocarditis. Prog Cardiovasc Dis 1979;22:169-80

14. Rogosa M, Hampp EG, Nevin TA, Wagner HN, Driscoll EJ, Baer PN. Blood sampling and cultural studies in the detection of postoperative bacteremia. J Am Dent Assoc 1960; 60:171-80

15. Durack DT, Gilliland BC, Petersdorf RG. Effect of immunization on susceptibility to experimental Streptococcus mutans and Streptococcus sanguis endocarditis. Infect Immun 1978;22:52-6

16. Scheld WM, Thomas JH, Sande MA. Influence of preformed antibody on experimental Streptococcus sanguis endocarditis. Infect Immun 1979;25:781-5

17. Van de Rijn. Role of culture conditions and immunization in experimental nutritionally variant streptococcal endocarditis. Infect Immun 1985;50:641-6

18. Durack DT, Beeson PB. Protective role of complement in experimental Escherichia coli endocarditis. Infect Immun 1977;16:213-7

19. Meddens MJM, Thompson J, Eulderink F, Bauer WC, Mattie $\mathbf{H}$, VanFurth $\mathbf{R}$. Role of granulocytes in experimental Streptococcus sanguis endocarditis. Infect Immun 1982;36: 325-32

20. Meddens MJM, Thompson J, Bauer WC, VanFurth R. Role of granulocytes and monocytes in experimental Escherichia coli endocarditis. Infect Immun 1984;43:491-6

21. Gould K, Ramirez-Ronda CH, Homes RK, Sanford JP. Adherence of bacteria to heart valves in vitro. J Clin Invest 1975;56:1364-70

22. Garvey GJ, Neu HC. Infective endocarditis - an evolving disease. A review of endocarditis at the Columbia-Presbyterian medical center, 1968-1973. Medicine (Baltimore) 1978;57: 105-27

23. Moore WEC, Holdeman LV, Smibert RM, Hash DE, Burmeister JA, Ranney RR. Bacteriology in severe periodontitis in young adult humans. Infect Immun 1982;38:1137-48

24. Auckenthaler R, Hermans PE, Washington JA. Group G streptococci bacteremia: clinical study and review of the literature. Rev Infect Dis 1983;5:196-204

25. Vartian C, Lerner PI, Shlaes DM, Gopalakrishna KV. Infections due to Lancefield group $\mathrm{G}$ streptococci. Medicine (Baltimore) 1985;64:75-88

26. Myhre EB, Kuusela P. Binding of human fibronectin to group A, C and G streptococci. Infect Immun 1983;40:29-34

27. Toy PT, Lai L-W, Drake TA, Sande MA. Effect of fibronectin on adherence of Staphylococcus aureus on fibrin thrombi in vitro. Infect Immun 1985;48:83-6

28. Scheld WM, Strunk RW, Balian G, Calderone RA. Microbial adhesion to fibronectin in vitro correlates with production of endocarditis in rabbits (4255). Proc Soc Exp Biol Med 1985:180:474-82 